\section{FUNDING AVAILABLE FOR MANAGEMENT COURSE}

UMD Professional has

announced that dentists and senior practice managers can benefit from part-funding towards their ILM dental business management course which starts in London and, for the first time, Leeds in early autumn. This course, which leads to the ILM Level 7 Diploma in Executive Management, offers a blend of practical workshops, webinars and one-to-one management mentoring, and provides 90 hours of verifiable CPD.

The part-funding, which is available for a limited period, contributes $£ 1,200$ towards the course fees, and a second delegate from the same practice can attend the course for half price.

www.umdprofessional.co.uk

\title{
MANAGEMENT TRAINING WITH FINANCIAL FLEXIBILITY
}

The Dentistry Business has been authorised to offer a two-year Level 4 Certificate of Higher Education in Dental Practice Management. Following on from its successful one-year, professional Certificate, the two-year course allows students to implement specific projects in their second year and gain university credits for their achievements.
In addition, this course is unique in allowing students to pay their fees via a Student Loan, providing financial flexibility over an extended period of time. The course will be offered initially in London and Manchester and other locations will be available subject to demand.

Call 01619285995 or email sim@thedentistrybusiness.com.

\section{RISK-FREE DIGITAL TRIAL}

Digital Dental offer the complete range of digital imaging units from Vatech, including Flex3D.

They are now offering a twoyear risk-free Flex 3D trial offer for clients purchasing their Flex $\mathrm{P}$ panoramic system. The Flex $\mathrm{P}$ produces superior quality digital panoramic images and enables a simple upgrade to the Flex 3D. www.digitaldental.co.uk.

\section{PERFECT OCCLUSAL BALANCE WITH CONFIDENCE}

Indent Systems are exclusive UK Distributors for T-Scan, the computerised occlusal force analysis device which takes the guesswork out of occlusion.

T-Scan enables dentists to enhance the accuracy of their diagnosis and treatment in a variety of clinical applications including implantology, periodontology and cosmetic dentistry. The patient simply bites on a thin sensor which relays changes in occlusal pressure as they move from initial contact into maximum intercuspation and excursive movements. These data are transmitted, in thousandths of a second increments, onto an easy to understand visual display.

From single unit restorations to full mouth rehabilitation it is important for patient comfort, as well as restoration longevity, to obtain a balanced occlusion with mutual anterior/posterior support. Using articulating paper alone cannot do this because it cannot measure force, balance or changes through time; T-Scan allows clinicians to perfect occlusal balance with accuracy and confidence.

Similarly, occlusal trauma is the cause of various oral pathologies. T-Scan enables clinicians to measure the force and timing of the functional bite to diagnose and treat the source of these problems. Likewise, because implants do not flex in a periodontal socket, controlling the force on a restored implant prosthesis is extremely difficult if working 'blind'. T-Scan enables clinicians to carefully monitor these occlusal forces and react accordingly. It can become the difference between success and failure.

For further information call 01932582900 , emailmike@indentsys.co.uk or visit the website www.indentsystems.com. 